\title{
Two step-production of acylglycerols containing a high proportion of docosapentaenoic acid from marine omega-3 oil and their oxidative stability
}

\author{
Zhongshui Yu ${ }^{\mathrm{a}}$, Jiankang Wang ${ }^{\mathrm{b}}$ and Fereidoon Shahidi ${ }^{\mathrm{a}^{*}}$
}

\begin{abstract}
aDepartments of Biochemistry, Memorial University of Newfoundland, St. John's, NL, Canada, A1B 3X9

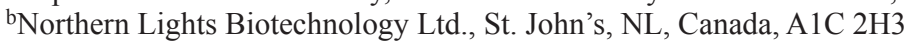

${ }^{*}$ Corresponding author: Fereidoon Shahidi, Departments of Biochemistry, Memorial University of Newfoundland, St. John's, NL, Canada, A1B 3X9. Tel: +1 (709) 864-8552; E-mail: fshahidi@mun.ca

DOI: $10.31665 /$ JFB. 2018.4168

Received: September 20, 2018; Revised received \& accepted: October 13, 2018

Citation: Yu, Z., Wang, J., and Shahidi, F. (2018). Two step-production of acylglycerols containing a high proportion of docosapentaenoic acid from marine omega-3 oil and their oxidative stability. J. Food Bioact. 4: 123-129.
\end{abstract}

\begin{abstract}
The objective of this study was to concentrate polyunsaturated fatty acid (PUFA) from seal blubber oil in an innovative manner to produce a high content of docosapentaenoic acid (DPA) in the resultant product. It also aimed at investigating the use of lipases as catalysts for synthesizing acylglycerols from glycerol and polyunsaturated fatty acid concentrates. Additionally, study of the oxidative stability of acylglycerols synthesized by lipases was intended. A two-stage urea complexation process was used to concentrate PUFA from seal blubber oil, giving rise to a DPA content of up to $24.0 \%$ in the product. Enzymatic synthesis of acyglycerols directly from glycerol and fatty acid concentrate was studied. Three lipases were used as biocatalysts for esterification. Lipase SP435 from Candida antarctica showed the highest activity for esterification. Effects of reaction parameters, namely temperature, time course and mole ratio of glycerol to fatty acid were followed with all three lipases. The optimal reaction time was $24 \mathrm{hr}$ at $30^{\circ} \mathrm{C}$ at a mole ratio of glycerol to fatty acid of $14: 1$. The maximum degree of acylglycerol synthesis was $>90 \%$. The effect of time course and mole ratio of glycerol to fatty acid on acylglycerols distribution was also determined. The oxidative stability of different samples under Schaal-oven conditions at $60{ }^{\circ} \mathrm{C}$ showed that the oxidative stability of acylglycerols was better than that of the corresponding fatty acid esters.
\end{abstract}

Keywords: Omega-3 DPA concentrate; Urea complexation; Enzymatic hydrolysis; Marine oil; Oxidative stability.

\section{Introduction}

The importance of marine oils in human nutrition and disease prevention was scientifically recognized three decades ago. Epidemiological studies in the early 1970s postulated that the low incidence of coronary heart disease of Greenland Eskimos might be related to their distinctive dietary habit and use of marine lipids rich in polyunsaturated fatty acids (PUFA) (Dyerberg et al., 1975). A large number of studies have been done on the potential benefits of the n-3 fatty acids in human disease since 1970's. The beneficial effects of PUFA have been ascribed to their ability to lower serum triacylglycerol and cholesterol levels and enhance their excretion, to increase membrane fluidity and by conversion to eicosanoids to reduce thrombosis. Physiological effects of n-3 fatty acids have been documented in the areas of heart and circulatory diseases, immune response and cancer. The first category includes prevention or treatment of atherosclerosis, thrombosis, hyperglyceridemia and high blood pressure. The second area relates to the treatment of asthma and arthritis. The third category includes treatment of cancer of breast, prostate and colon (Shahidi, 1998).

It has been suggested that PUFA concentrates devoid of more saturated fatty acids are much better than marine oils themselves since they allow keeping the daily intake of total lipids as low as possible (Hassgsma et al., 1982). Several methods are available 
for large-scale production of PUFA concentrates. The available methods include adsorption chromatography (Adlof and Emiken, 1985), fractional to molecular distillation (Berger and McPherson, 1979), enzymatic splitting (Yadwad et al., 1991), low-temperature crystallization (Brown and Kolb, 1955), supercritical fluid extraction (Yamagouchi et al., 1986) and urea complexation (Ratnayake et al., 1988). Each technique has its own advantages and drawbacks.

The simplest and most efficient technique for obtaining w-3 PUFA concentrates in the form of free fatty acids is urea complexation. This is a well established technique for elimination of saturated and monounsaturated fatty acids. Urea alone crystallizes in a tightly packed tetragonal structure with channels of 5.67 A diameter. However, in the presence of long straight chain molecules it crystallizes in a hexagonal structure with channels of 8-12 A diameter within the hexagonal crystals. The channels formed, in the presence of long chain unbranched molecules, are sufficiently large to accommodate aliphatic chains. While straight chain saturated fatty acids with six carbon atoms or more are readily adducted, the presence of double bonds in the carbon chain increases the bulk of the molecule and reduces the likelihood of its complexation with urea. The saturated and monounsaturated fatty acids easily complex with urea and crystallize out on cooling and may subsequently be removed by filtration. Liquid or non-urea complexed fraction is enriched in n-3 PUFA. Many publications have described the application of urea complexation for production of PUFA concentrates. Recently, this method was used to concentrate n-3 PUFA from seal blubber oil (Wanasundara and Shahidi, 1999; Shahidi et al., 1994). Under optimum conditions, a maximum concentration of n-3 PUFAs (88.2\%) was achieved. Among the major n-3 PUFA, more than $80 \%$ of docosahexaenoic acid (DHA) and eicosapentaenoic acid (EPA) was recovered. Urea complexation has the advantage that complexed crystals are extremely stable, and filtration does not have to necessarily be carried out at the very low temperatures which solvent crystallization of fatty acids would require.

Lawson and Hughes (1988) have pointed out that EPA, docosapentaenoic acid (DPA) and DHA are completely absorbed only as acylglycerols, whereas free fatty acid forms are less acceptable in foods. Therefore, acylglycerols are considered to be the most desirable form. In recent years, the use of lipases as biocatalysts for interesterification has become of great industrial interest for the production of useful triacylglycerol products. This is mainly because of the specificity of these enzymes with respect to acylglycerol positions and fatty acid types. The high temperatures $\left(220-250{ }^{\circ} \mathrm{C}\right)$ used in current chemical technologies for acylglycerol synthesis and hydrolysis of fats and oils cause degradation of fatty acids and discoloration of products (McNeill et al., 1991). This causes a loss of product quality and yield, particularly for highly unsaturated and hydroxyl-containing fatty acids. Such disadvantages may be overcome by using lipases, which react under mild conditions and allow production of desired products without leaving harmful residues.

Fish oils are much more prone to deterioration than are other fats or oils. A very important problem remains in oil extraction, processing and preservation from free radical oxidative deterioration. Lipid oxidation may compromise the safety, nutritional quality and shelf-life of edible oils. Lipid oxidation products are implicated in the disruption of biological membranes, formation of age pigments in damaged membrane inactivation of enzymes and damage to proteins. Proper understanding of lipid oxidation mechanisms and measurement techniques as well as use of synthetic and natural antioxidants will improve the ability to control lipid oxidation and therefore prevent or minimize oxidative deterioration of foods as well as oxidative damage in the human body.

There are many catalytic systems that can oxidize lipids. Among these are light, temperature, enzymes, metals, metalloproteins and microorganisms. Most of these reactions involve some type of free radical and/or reactive oxygen species. Since enzymes and metalloproteins are labile to heat denaturation, lipoxygenase activity is normally absent in a refined oil. Therefore, oxidation catalyzed by enzymes does not create a problem during storage and subsequent use of fats and oils. Autoxidation is the process of oxidation induced by air. Oxidative reactions of lipids are greatly accelerated at higher temperatures. The oxidation of lipids at higher temperatures is known as thermal oxidation. Autoxidation and thermal oxidation are more directly involved in the oxidation of fatty acids during storage and processing.

\section{Materials and methods}

\subsection{Materials}

Fatty acid methyl esters standards were purchased from Nu-Check company (Elysian, MN). Propanal, hexanal and heptanal were purchased from Sigma (St. Louis, MO). The lipases Novozym-435 from Candida antarctica and IM60 from Mucor miehei were provided by Novo Nordisk (Bagsvaerd, Denmark). The lipase PS30 from Pseudomonas sp. wasprovided by Amano enzyme, USA Co., Ltd. (Troy, VA). DPA rich-marine omega-3 oil (seal blubber oil) was obtained from local sources in Newfoundland. All other chemicals used in this study were of American Chemical Society (ACS) grade or higher.

\subsection{Methods}

\subsubsection{Preparation of omega-3 rich-free fatty acids}

The method used for preparing free fatty acids from seal blubber oil was the same as that described by Wanasundara (1999) with minor modification. To $100 \mathrm{~g}$ of seal blubber oil, $23 \mathrm{~g}$ of $\mathrm{KOH}$, $44 \mathrm{ml}$ of deionized water and $264 \mathrm{ml}$ of ethanol $(95 \%, \mathrm{v} / \mathrm{v})$ were added. Then, tertiary-butylhydroquinone (TBHQ) was added in the mixture to rich a concentration of $200 \mathrm{ppm}$. The mixture was refluxed under nitrogen at $62{ }^{\circ} \mathrm{C}$ for $1 \mathrm{~h}$. To the saponified mixture, $50 \mathrm{ml}$ ethanol $(95 \% \mathrm{v} / \mathrm{v})$ and $250 \mathrm{ml}$ deionized water were added. The mixture was extracted with $200 \mathrm{ml}$ of hexane for twice, and the hexane layer was discarded each time. The final aqueous layer was acidified with $6 \mathrm{M} \mathrm{HC1}$ to $\mathrm{pH}=1.0$, then $200 \mathrm{ml}$ of hexane was added to the resultant free fatty acids followed by thorough mixing. The hexane layer was removed and then dried over anhydrous sodium sulphate, and the solvent removed using a rotary evaporator at $40^{\circ} \mathrm{C}$.

\subsubsection{Preparaton of DPA rich-fatty acid concentrate using the two step-urea complexation}

DPA rich-fatty acid concentrate was obtained using the two stepurea complexation, which was originated from the method described by Wanasundara (1999) with modifcations. In the first step, $20 \mathrm{~g}$ of free fatty acids mixture obtained from seal blubber oil was added in the $20 \%(\mathrm{w} / \mathrm{v})$ urea solution at $60{ }^{\circ} \mathrm{C}$ in ethanol $(95 \%)$. 
The mixture was allowed to crystallize at $4{ }^{\circ} \mathrm{C}$ in a cold room for 8 $\mathrm{hr}$. The urea complexed fraction was subsequently separated from the liquid by filtration. The crystal was dissolved in water and acidified to $\mathrm{pH} 4-5$ with $6 \mathrm{M} \mathrm{HCl}$, and an equal volume of hexane was subsequently added to the solution. The mixture was stirred thoroughly for one hour. The hexane layer containing liberated fatty acids was separated from the aqueous layer. The hexane layer was washed with distilled water in order to remove any remaining urea, and then it was dried over anhydrous sodium sulphate. The solvent was removed at $40{ }^{\circ} \mathrm{C}$ using a rotary evaporator. The free fatty acids obtained from step one was mixed with urea $(20 \% \mathrm{w} / \mathrm{v})$ in $95 \%$ ethanol heated at $60{ }^{\circ} \mathrm{C}$. The mixture was maintained in a freezer at $-18{ }^{\circ} \mathrm{C}$ for $24 \mathrm{hr}$, where is the temperature is much lower than that used in step one. The non-urea complexed and urea complexed fractions were separated upon the completion of the complexation. The filtrate was diluted with an equal volume of water and acidified to $\mathrm{pH} 4-5$ with $6 \mathrm{M} \mathrm{HC1}$, and then an equal volume of hexane was added followed by thorough stirring for one hour. The mixture was then transferred to a separatory funnel, where the hexane layer was separated from the aqueous layer. The hexane layer was washed with distilled water to remove any remaining urea and then dried over anhydrous sodium sulphate. The solvent was removed at $40{ }^{\circ} \mathrm{C}$ using a rotary evaporator.

\subsubsection{Synthesis of DPA rich-acylglycerols}

DPA rich-acylglycerols were synthesized from glycerol and the DPA rich-fatty acid concentrate. In a 50-ml Erlenmeyer flasks, 2 $\mathrm{g}$ of glycerol was combined with $0.4 \mathrm{~g}$ DPA rich-fatty acid concentrate and $50 \mathrm{mg}$ lipase of SP435, followed by the addition of $100 \mu 1$ of water and $2 \mathrm{ml}$ of hexane. The reaction mixture was then flushed with nitrogen for $30 \mathrm{~s}$. The mixture was stirred in an orbital shaker at $180 \mathrm{rpm}$ and at different temperatures $(20,30$, 40 and $50{ }^{\circ} \mathrm{C}$ ) and various time periods $(3-48 \mathrm{hr})$. The esterification reaction was stopped by addition of $20 \mathrm{ml}$ of acetone/ethanol mixture $(1: 1 \mathrm{v} / \mathrm{v})$. The free fatty acids in the resultant mixture were titrated with $0.1 \mathrm{M} \mathrm{NaOH}$ to a phenolphthalein endpoint. After the free fatty acids were titrated, $4 \mathrm{ml}$ of $0.1 \mathrm{M} \mathrm{NaOH}$ and $50 \mathrm{ml}$ of deionized water were added to the mixture. The mixture was then transferred to a reparatory funnel and thoroughly mixed with $25 \mathrm{ml}$ of diethyl ether three times. The lower aqueous layer was discarded. The collected diethyl ether layer was dried over anhydrous sodium sulphate. The solvent was removed from the synthesized acylglycerols using a rotary evaporator at $40^{\circ} \mathrm{C}$. The components were identified and quantified by TLC-F1D. The mixture was developed using hexane/diethyl ether/formic acid $(80: 20: 1, \mathrm{v} / \mathrm{v} / \mathrm{v})$ as the solvent system.

\subsubsection{Determination of fatty acid composition of synthesized DPA rich-acylglycerols}

Triacylglycerols (TAG), diacylglycerols (DG) and monoacylglycerols (MG) in synthesized DPA rich-acylglycerols were separated by thin layer chromatography (TLC). The products extracted from reaction mixture were dissolved in hexane and applied to several TLC plates $(20 \times 20 \mathrm{~cm}$; Silica gel, 2-25 um mean particle size, 500 um thickness, with dichlorofluorescein, Sigma, St. Louis, MO). Thirty milligrams acylglycerols were loaded onto each plate. The plates were developed in solvent systems of hexane/diethyl ether/formic acid (70:30:1, v/v/v). After drying, the bands were located by viewing under a short $(254 \mathrm{~nm}) \mathrm{UV}$ light. The three bands were scraped and then extracted with diethyl ether three times as described previously. The ether layer was evaporated under nitrogen to obtain TG, DG and MG. The fatty acid composition of each acylglycerol was analyzed using GC.

\subsubsection{Oxidative stability test}

Three samples were prepared for oxidative stability test. The samples were purified by column chromatography. One hundred twenty grams of silicic acid (100 mesh) were washed with 1,000 $\mathrm{ml}$ of deionized water three times; the silicic acid was dehydrated with $200 \mathrm{ml}$ methanol three times. The dehydrated silicic acid was dried in an oven at $100{ }^{\circ} \mathrm{C}$ for $6 \mathrm{hr}$ and then dried in a furnace at $200{ }^{\circ} \mathrm{C}$ overnight. The dried silicic acid was mixed with 400 $\mathrm{ml} \mathrm{n}$-hexane and degassed by sonication for $15 \mathrm{~min}$. Afterwards, the silicic acid in hexane was loaded onto the column (diameter: $2 \times 40 \mathrm{~cm}$ ) to which hexane was added $(3 \mathrm{ml} / \mathrm{min})$ for $5 \mathrm{hr}$. The acylglycerols were loaded and the column washed with hexane (3 $\mathrm{ml} / \mathrm{min}$ ), hexane/diethyl ether, and diethyl ether, respectively. The collections were monitored concurrently by TLC. The collection tubes for each of the TG, MG and DG were combined and the solvent was evaporated at $40{ }^{\circ} \mathrm{C}$.

Comparison of the oxidative stability of different samples was carried out under Schaal-oven test conditions at $60{ }^{\circ} \mathrm{C}$. It is generally accepted that each day of storage of lipid under Schaal-oven test conditions at $60{ }^{\circ} \mathrm{C}$ is equivalent to one month of storage at ambient temperatures. The specifications of the experiments carried out under Schaal-oven test conditions were as follows. Each sample $(2 \mathrm{~g})$ in triplicate, was placed in test tubes $(10 \mathrm{~mm} \times 12 \mathrm{~cm})$ and stored in a forced air oven (Thelco, Model 2, Precision Scientific Co., Chicago, IL) at $60^{\circ} \mathrm{C}$. The oxidative stability was determined by chemical methods - Conjugated dienes (Meyer, 1993); 2-thiobarbituric acid reactive substances value (Wettasinghe and Shahidi, 1999); and headspace volatiles (Wettasinghe and Shahidi, 1999). The samples were removed periodically at $0,6,12,24,48$ and $72 \mathrm{hr}$ from the oven, cooled to room temperature, flushed with nitrogen, capped and stored at $-20{ }^{\circ} \mathrm{C}$ until analysis.

\subsubsection{Hydrolysis of triacylglycerols by pancreatic lipase}

Hydrolysis of purified triacylglycerol by pancreatic lipase was carried out according to following method. Tris-hydrochloric acid buffer $(5 \mathrm{ml}, 1.0 \mathrm{M}, \mathrm{pH}=8.0), 0.5 \mathrm{ml}$ of calcium chloride $(2.2 \%$, $\mathrm{w} / \mathrm{v})$ and $1.25 \mathrm{ml}$ of sodium taurocholate $(0.05 \%, \mathrm{w} / \mathrm{v})$ were added to $25 \mathrm{mg}$ of oil in a glass test tube. The whole mixture was allowed to equilibrate at $40^{\circ} \mathrm{C}$ in a water bath for $1 \mathrm{~min}$ and subsequently $5.0 \mathrm{mg}$ of porcine pancreatic lipase (EC. 3.1.1.3, Sigma) were added to it. The mixture was then place in a Gyrotory water bath shaker (Model G76, New Brunswick Scientific Co. Inc., New Brunswick, NJ) at $180 \mathrm{rpm}$ under nitrogen for $1 \mathrm{hr}$ at $40^{\circ} \mathrm{C}$. Ethanol $(5 \mathrm{ml})$ was added to stop the enzymatic hydrolysis followed by addition of $5.0 \mathrm{ml}$ of $6 \mathrm{M} \mathrm{HC1}$. The hydrolytic products were extracted three times with $50 \mathrm{ml}$ of diethyl ether and the ether layer was washed twice with distilled water and dried over anhydrous sodium sulphate. After removal of the solvent under vacuum at 40 ${ }^{\circ} \mathrm{C}$, the hydrolytic products were separated on TLC plates $(20 \times$ $20 \mathrm{~cm}$, silica gel, $225 \mu \mathrm{m}$ mean particle size, 50,011 m thickness; Sigma, St. Louis, MO). The plates were developed using hexane/ diethyl ether/ acetic acid (70:30:1, v/v/v). The bands were scraped off and their lipids were extracted into diethyl ether three times and subsequently used for fatty acid analysis by the gas chromatography of their methyl esters. 
Table 1. The contents of EPA, DPA and DHA in the urea complexed and non-urea complexed fractions under different conditions

\begin{tabular}{|c|c|c|c|c|c|c|c|c|}
\hline \multirow{2}{*}{ Urea to fatty acid ratio } & \multicolumn{4}{|c|}{ Urea complexed fraction } & \multicolumn{4}{|c|}{ Non-urea complexed fraction } \\
\hline & DHA & DPA & EPA & Yield (\%) & DHA & DPA & EPA & Yield (\%) \\
\hline 3 & 0.53 & 3.06 & 2.18 & 72 & 37.4 & 7.48 & 26.3 & 20 \\
\hline 3.3 & 0.71 & 3.78 & 3.1 & 72.3 & 40.1 & 4.75 & 25.2 & 18.7 \\
\hline 3.5 & 0.85 & 4.16 & 3.91 & 75 & 44.7 & 3.08 & 23.9 & 16.5 \\
\hline 4.5 & 1.95 & 4.18 & 5.65 & 75 & 50.2 & 2.82 & 18.9 & 12 \\
\hline
\end{tabular}

Table 2. The contents of EPA, DPA and DHA in the original free fatty acid, first and second concentrates

\begin{tabular}{llll}
\hline & EPA (\%) & DPA (\%) & DHA (\%) \\
\hline Original fatty acids & $7.48 \pm 0.22$ & $4.03 \pm 0.15$ & $8.32 \pm 0.17$ \\
First step concentrates (UCF) & $3.10 \pm 0.56$ & $3.78 \pm 0.32$ & $0.71 \pm 0.16$ \\
Second step concentrates (NUCF) & $20.80 \pm 1.58$ & $24.00 \pm 1.05$ & $3.85 \pm 0.45$ \\
\hline
\end{tabular}

\section{Results and discussion}

\subsection{Preparation of docosapentaenoic acid (DPA) rich concen- trate from seal blubber oil via urea complexation}

A concentrate of docosapentaenoic acid (DPA) was obtained by urea complexation of fatty acids of seal blubber oil. Urea complexation is a well-established technique for elimination of saturated and monounsatureated fatty acids. Initially, the triacylglycerols of the seal blubber oil were split into their constituent fatty acids by alkaline hydrolysis. The saturated and monounsaturated fatty acids are easily complexed with urea and crystallize out on cooling and may subsequently be removed by filtration. Straight-chain saturated fatty acids with six carbon atoms or more are readily complexed, the presence of double bonds in the carbon chain increases the bulk of the molecule and reduces the likehood of its complexation with urea. Monounsaturated fatty acids are more readily complexed as compared to diunsaturated fatty acids, which, in turn, are more easily complexed than triunsaturated fatty acids. Therefore, the formation of fatty acid-urea adduct depends on the degree of undaturation of fatty acids. In this investigation, the influence of the urea to fatty acid ratio on the concentration of DPA in the first time concentrate was studied (Table 1). A higher urea to fatty acid ratio was used under this condition; most of the DHA and more than half of EPA were in the non-urea complexed fraction. But most of the DPA remained in the urea complexed fraction. Table 1 shows that the urea to fatty acid ratio of 3.3 was the best. Under this condition, a minimum DHA and EPA in the urea complexed fraction was obtained and most of the DPA was in the urea complexed fraction.

In the second step, a low urea to fatty acid ratio was used to concentrate the DPA and EPA from the urea complexed fraction after the first process. A 2.5 ratio of urea to fatty acids was used. Under this condition, most of the DPA and EPA in the free fatty acids were in the non-urea complexed fraction (Table 2).

The main fatty acid compositions of the original seal blubber oil and that of the concentrates produced from it are given in Table 3. The major fatty acids present in the seal blubber oil were $16: 1$ (17.55\%), 18:1 (21.62\%) and 20:1 (12.30\%). DPA was enriched from $4.03 \%$ to $24.0 \%$. EPA also was enriched from $7.48 \%$ to $20.8 \%$. However, DHA was decreased from $8.32 \%$ to $3.85 \%$. Recently, urea complexation of seal blubber oil was attempted for producing n-3 PUFA concentrates (Wanasundara and Shahidi, 1999). Among the major n-3 PUFA, DHA was found almost exclusively in the NUCF of seal blubber oil under selected experimental conditions.

\subsection{Enzymatic synthesis of acylglycerols}

Temperature is well known factor affecting enzyme activity. The rate of enzyme activity does increase as the environment heats up, until a maximum rate is reached. Table 4 illustrates the effect of temperature on lipase-catalyzed synthesis by three lipases. The temperature range tested was $20-50{ }^{\circ} \mathrm{C}$. The degree of synthesis

Table 3. Fatty acid composition of the original oil and the concentrate

\begin{tabular}{lll}
\hline Fatty acids & Original oil (\%) & Concentrate (\%) \\
\hline $16: 00$ & $7.34 \pm 0.38$ & $0.15 \pm 0.05$ \\
$16: 1 \mathrm{n}-7$ & $17.55 \pm 1.21$ & $18.86 \pm 0.90$ \\
$18: 1 \mathrm{n}-9$ & $21.62 \pm 0.83$ & $0.36 \pm 0.11$ \\
$18: 3 \mathrm{n}-3$ & $0.60 \pm 0.13$ & $2.93 \pm 0.21$ \\
$20: 1 \mathrm{n}-9$ & $12.30 \pm 0.32$ & $0.10 \pm 0.04$ \\
$20: 5 \mathrm{n}-3$ & $7.48 \pm 0.22$ & $20.77 \pm 1.58$ \\
$22: 5 \mathrm{n}-3$ & $4.03 \pm 0.15$ & $24.02 \pm 1.05$ \\
$22: 6 \mathrm{n}-3$ & $8.32 \pm 0.17$ & $3.85 \pm 0.45$ \\
\hline
\end{tabular}


Table 4. Effect of temperature on the degree of synthesis

\begin{tabular}{llll}
\hline \multirow{2}{*}{ Temperature $\left({ }^{\circ} \mathrm{C}\right)$} & \multicolumn{2}{c}{ Degree of Synthesis (\%) } \\
\cline { 2 - 4 } & PS30 & IM60 & SP435 \\
\hline 20 & $26.21 \pm 2.83$ & $59.10 \pm 2.83$ & $68.35 \pm 1.06$ \\
30 & $51.56 \pm 5.39$ & $81.12 \pm 4.52$ & $88.98 \pm 1.40$ \\
40 & $52.87 \pm 10.79$ & $80.86 \pm 1.32$ & $89.29 \pm 0.38$ \\
50 & $62.14 \pm 0.81$ & $81.89 \pm 2.48$ & $90.05 \pm 1.57$ \\
\hline
\end{tabular}

increased as the temperature was increased. When the temperature was higher than $30^{\circ} \mathrm{C}$, the degree of synthesis did not change much. In this table, the data also indicate that the best enzyme among three lipases used was SP435.

\subsection{Time course}

Figure 1 shows changes in the degree of synthesis with time for different lipases. This is useful in monitoring the progress of enzyme-catalyzed reactions. It is also used to determine the shortest time necessary to obtain the highest degree of synthesis and minimize the production costs. Acylglycerols were synthesized by three lipases. For lipases SP435 and 1M60, the degree of synthesis was more than $80 \%$ after $12 \mathrm{hr}$ of incubation in hexane (Fig. 1). For lipase PS30, the degree of synthesis depended more on the reaction time. However, Figure 1 shows that lipases SP435 and 1M60 were better than lipase PS30 for synthesis of acylglycerols. Based on these results, the lipase SP435 was selected for production of acylglycerols from PUFA concentrates.

\subsection{Effect of mole ratio of glycerol to free fatty acids in the concentrates}

The effects of glycerol/fatty acids mole ratio on degree of synthesis as catalyzed by the three lipases are shown in Figure 2. As the number of moles of glycerol increased, the degree of synthesis was also increased. Compare to a 1:1 mole ration, the degree of synthesis increased by more than 4 times at a glycerol/fatty acids ratio of 14:1 for lipase SP435 and 1M60. However, this resulted in the formation of more of the mono- and diacylglycerols as compared to triacylglycerols. In cases when the formation of triacylglycerols is intended, the ratio of free fatty acids to glycerol should be in the

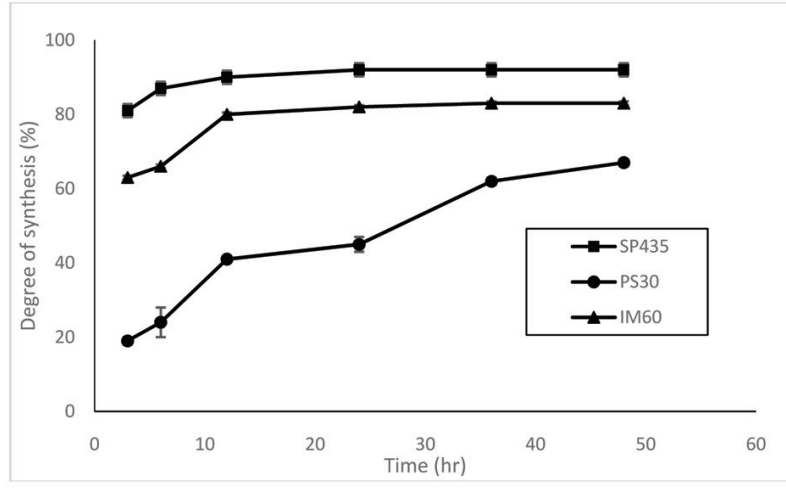

Figure 1. Time course of esterification by lipases. The reaction was conducted at $30^{\circ} \mathrm{C}$. opposite direction.

\subsection{Distribution of acyigiycerois synthesized by lipase SF-435}

The acylglycerols synthesized by lipase 435 were separated by thin layer chromatography. The results showed that the relative content of triacylglycerols was dependant on the reaction time (Fig. 3). At a short time period, diacylglycerols were much higher than triacylglycerols and monoacylglycerols. At all reaction period tested, monoacylglycerols were always at a low level and nearly constant. For diacylglycerols, the concentration went down as the reaction progressed. On the other hand, the concentration of triacylglycerols increased as the reaction continued. After $24 \mathrm{hr}$, the concentration of triacylglycerols and diacylglycerols reached a plateau. The results show that the relative content of triacylglycerols will also reach a maximum value. For synthesis of acylglycerols, the more triacylglycerols in the product is considered better.

The ratio of glycerol to fatty acids also affected the distribution of acylglycerols synthesized by lipases. Figure 4 shows that the proportion of triacylglycerols decreased as the ratio of glycerol to fatty acids increased. However, the proportion of diacylglycerols increased as the ratio of glycerol to fatty acids increased.

\subsection{Positional distributions of fatty acids of triacylglycerols}

The fatty acid composition of the sn- 2 and sn- $1+$ sn- 3 positions of the triacylglycerols performed by pancreatic lipase hydrolysis. Pancreatic lipase is used to hydrolyze quite specifically the fatty acids esterified to the primary positions of triacylglycerols yielding 2-monoacylglycerols, the fatty acid composition of which accurately reflects that of

position 2 in the original triacylglycerols. The results showed

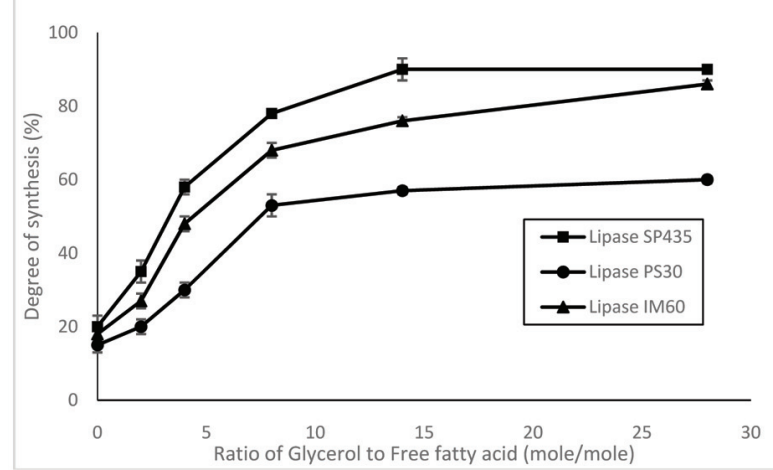

Figure 2. Effects of glycerol content on degree of synthesis by lipases. The reaction was conducted at $30^{\circ} \mathrm{C}$ for $24 \mathrm{hr}$. 


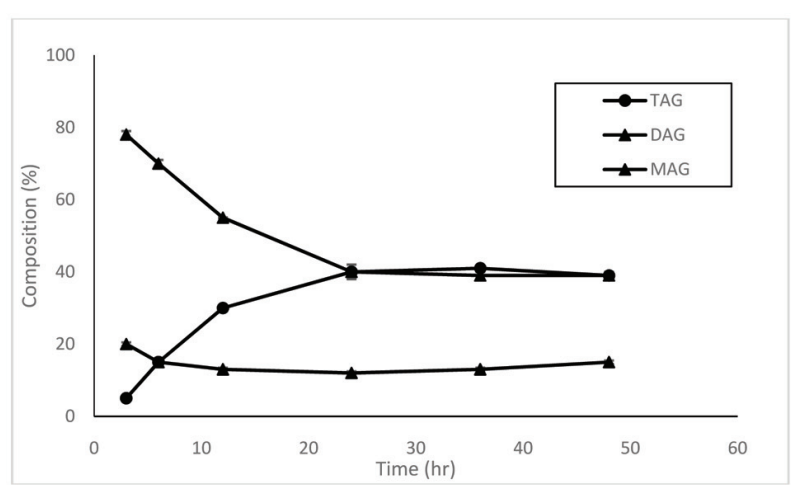

Figure 3. Distribution of acylglycerols synthesized by lipase SP435 over different time periods. The reaction was conducted at $30^{\circ} \mathrm{C}$.

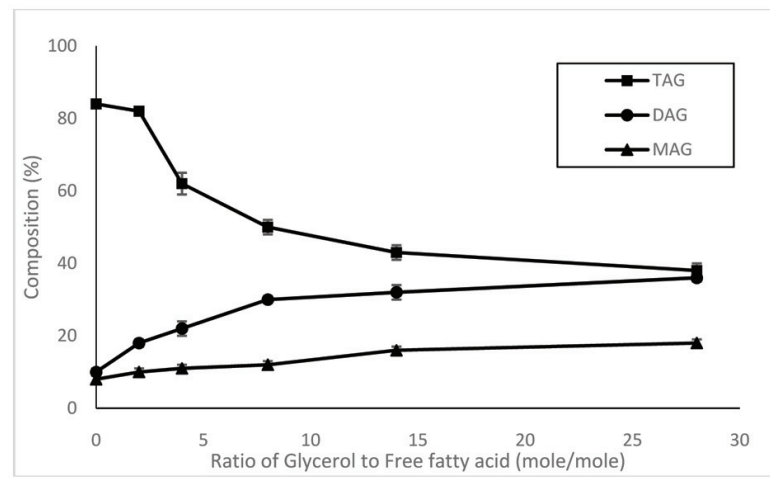

Figure 4. Distribution of acylglycerols synthesized by lipase SP435 over different time periods. The reaction was conducted at $30^{\circ} \mathrm{C}$.

that there was no specific selection for each position when lipase SP435 was used.

\subsection{Oxidative stability of acylglycerols synthesized by lipase SP435}

The enzymatically synthesized oils procured under optimum conditions were assessed for their oxidative stability by accelerated oxidation under Schaal oven conditions at $60{ }^{\circ} \mathrm{C}$ over a $96 \mathrm{hr}$ pe-

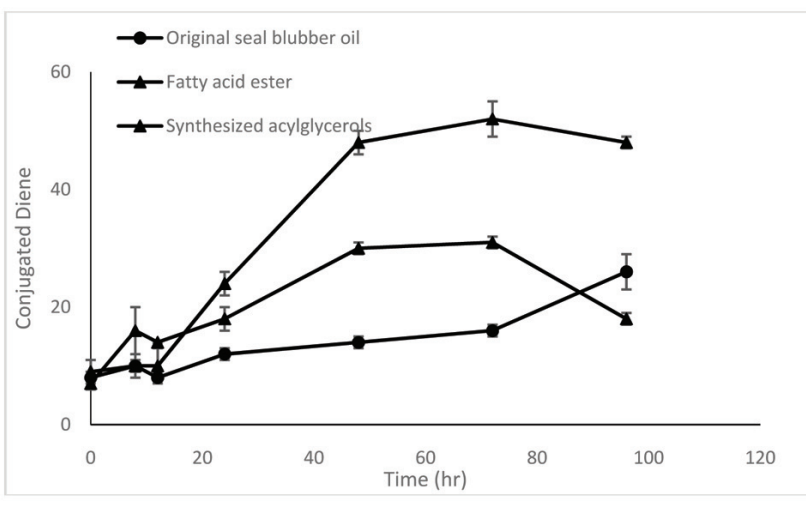

Figure 5. Conjugated diene value of different samples. The test was carried out at $60^{\circ} \mathrm{C}$ for $96 \mathrm{hr}$.

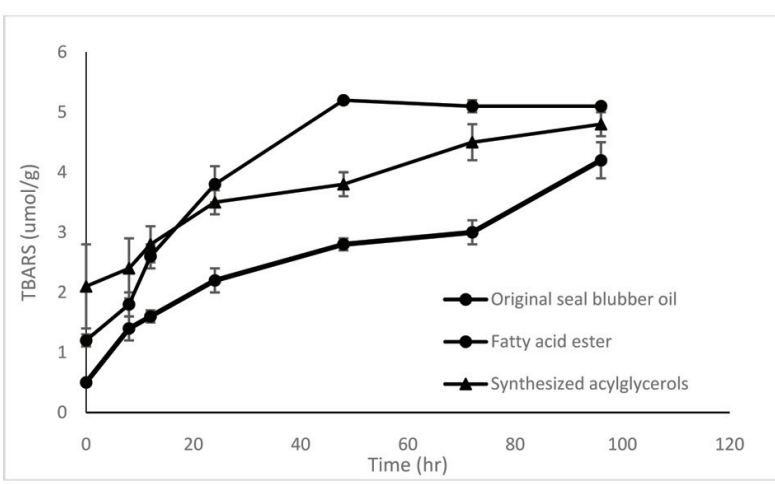

Figure 6. TBARS value of different samples. The test was carried out at $60^{\circ} \mathrm{C}$ for $96 \mathrm{hr}$.

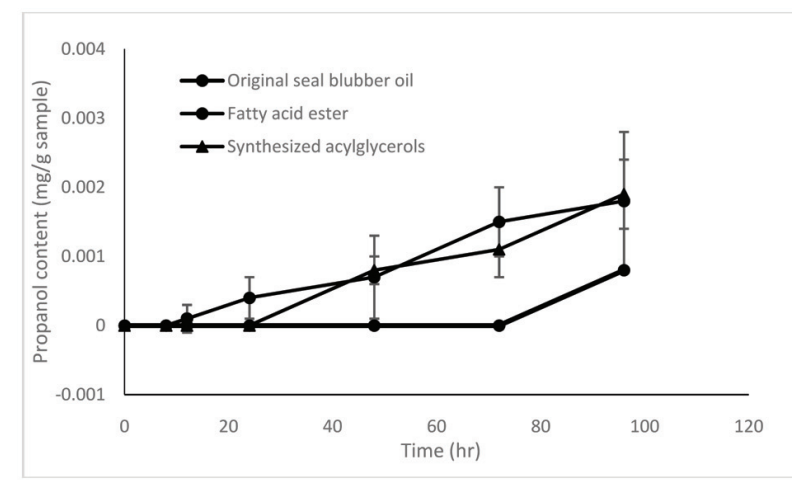

Figure 7. Propanal content of different samples. The test was carried out at $60^{\circ} \mathrm{C}$ for $96 \mathrm{hr}$.

riod. Progression of oxidation was monitored by determine conjugated dienes (CD), propanal content and TBARS (thiobarbituric acid reactive substances) values.

In this study, three samples were used - original seal blubber oil, and concentrates of fatty acid esters and triacylglycerols synthesized by lipase SP435. The results show that the oxidative stability of acylglycerols was generally better than that of fatty acid esters, despite the fact that their fatty acid compositions were the same (Figs. 5-7).

\section{Conclusions}

To date, most of the published literature on production of PUFA has focused on docosahexaenoic acid (DHA) and eicosapentaenoic acid (EPA). However, urea complexation proved to be a simple technique for producing PUFA with a high proportion of DPA using seal blubber oil as starting material. Acylglycerols were easily synthesized from free fatty acid and glycerol using enzymatic method. The degree of synthesis could reach as high as $90 \%$. Comparing to chemical means, mild condition of synthesis using lipase was better for PUFA. The results of this study showed that the oxidative stability of acylglycerols was better than free fatty acid ester, but worse than original oil.

\section{References}

Adlof, R.O., and Emiken, E.A. (1985). The isolation of omega-3 polyunsatu- 
rated fatty acids and methyl esters of fish oils by silver resin chromatography. J. Am. Oil Chem. Soc. 62: 1592-1595.

Berger, R., and McPherson, W. (1979). Fractional distillation. J. Am. Oil Chem. Soc. 56: 743-746A.

Brown, L.B., and Kolb, D.X. (1955). Application of low temperature crystallization in the preparation of the fatty acids and their compounds. Prog. Chem. Fats Lipids 3: 57-94.

Dyerberg, J., Bang, H.O., and Hjorne, N. (1975). Fatty acid composition of the plasma lipids in Greenland Eskimos. J. Am.Clin. Nutr. 28: 958-962.

Haafsma, N., Gent, C.M., Luten, J.B., Jong, R.W., and Doom, E. (1982). Preparation of an o 3 fatty acid concentrate from cod liver oil. J. Am. Oil Chem. Soc. 59: 117-118.

Lawson, L.D., and Hughes, B.G. (1988). Absorption of eicosapentaenoic acid and docosahexaenoic acid from fish oil triacylglycerols or fish oil ethyl esters co-ingested with high-fat meal. Biochem. Biophys. 152: 960-963.

McNeill, G.P., Shimizu, S., and Yamane, T. (1991). High-yield enzymatic glycerolysis of fats and oils. J. Am. Oil Chem. Soc. 68: 1-5.

Meyer, A.S. (1993). Conjugated dienes and trienes - critical assessment of their value as oxidation descriptors of fish oil. Nord. Lipid Sytnp. Proc. 17: 169-171.
Ratnayake, W.M.N., Olisson, B., Matthews, D., and Ackman, R.G. (1988). Preparation of omega-3 PUFA concentrates from fish oils via urea complexation. Fat Sci. Technol. 90: 381-386.

Shahidi, F., Amorowicz, R., Synowiecki, J., and Naczk, M. (1994). Extraction and concentration of omega-3 fatty acids of seal blubber in Developments in Food Engineering. In: Yano, T.Matsuno, R., and Nakamura, K. (Ed.). Blackie Academic and Professional, New York, NY, pp. 627-629.

Shahidi, F. (1998). Seal Fishery and Product Development. ScienceTech Publishing Company, St. John's, NF, pp. 99-136.

Wanasundara, U.N., and Shahidi, F. (1999). Concentration of omega-3 polyunsaturated fatty acids of seal blubber oil by urea complexation: optimization of reaction conditions. Food Chem. 65: 41-49.

Wettasinghe, M., and Shahidi, F. (1999). Antioxidant and free radical-scavenging properties of ethanolic extracts of defatted borage (Borago officinalis L.) seeds. Food Chem. 67: 399-414.

Yadwad, V.B., Ward, O.P., and Noronha, L.C. (1991). Application of lipase to concentrate the docosahexaenoic acid fraction of fish oil. Biotech. Bioeng. 38: 956-959.

Yamagouchi, I., Murakami, W., Nakano, H., Konosu, S., Kokura, T., Yamamoto, H., Kosaka, M., and Hata, K. (1986). Supercritical carbon dioxide extraction of oils from Antarctic. 